\title{
Consensual Relationships in the Academic Field: A Phenomenological Understanding
}

\author{
Aljoriz M. Dublin \\ University of the Visayas, Cebu City, The Philippines \\ Email: aljoriz@gmail.com, aljoriz@uv.edu.ph \\ Received 3 February 2015; accepted 26 February 2015; published 27 February 2015 \\ Copyright $@ 2015$ by author and Scientific Research Publishing Inc. \\ This work is licensed under the Creative Commons Attribution International License (CC BY). \\ http://creativecommons.org/licenses/by/4.0/ \\ (c) (i) Open Access
}

\begin{abstract}
The problem this study will address is the existence of consensual relationship between learners and their instructors. The purpose of this phenomenology is to understand lived experiences in relation to consensual relationship between ten teachers and ten students of XXX University. It uses phenomenological analysis to explore the lived experiences of informants. Qualitative data were collected through the use of interview protocols collected at a conducive place for informants of their selection. Some themes developed were fear, physical attraction, transference and countertransference. The study points to the natural existence of consensual relationship in the academe and learners.
\end{abstract}

Keywords

Consensual Relationships, Phenomenology

\section{Introduction}

Purpose of the Study The purpose of this phenomenology is to understand the lived experiences in relation to consensual relationship between ten college teachers and ten college students of XXX University. At this stage of the research, consensual relationship is defined as a romantic relationship between teachers and learners, which can either be platonic or graduating to purely sexual in nature. This study makes use of phenomenological analysis to explore the lived experiences of informants.

The Rationale The teacher's role is holistic to such extent that student may end up emulating their teachers. As evidenced by Stake and Noonan [1] teacher attraction may result in confidence and academic growth to samesex grouping between teachers and learners, whereas the opposite-sex model group shows that teacher attraction may not result in academic growth. But why is there an attraction between learners and instructors? A possible explanation can be found in popular methods of psychotherapy, which are transference and countertransference. 
Transference is defined by Guralnik [2] as "a reproduction of emotions relating to repressed experiences, especially the childhood, and the substitution of another person for the original object of the repressed impulses". It is believed that when a person reminds us of someone whom we admire or love, our mind assumes that we are in love with that particular person. In the academic field, Transference may occur when a learner admires his instructor so much since that person reminds him of someone he admire most or used to love. Gabbard [3] proves that transference occurs among therapists and patients in varying degrees from plain platonic relationship to sexual ones.

Conversely, countertransference is defined by Freud [4] as "a result of the patient's influence on [the physician's] unconscious feeling". In short, it is the propensity of the physician's tendency to fall for the patient. Countertransference is simply a situation where the instructor falls for the learner, possibly reminding him of a failed relationship or even a rebound from a previous relationship. Smith [5] proved that countertransference among medical students was deleterious to their interviewing skills, and he surmised that had these students not developed feelings towards their patients their interviewing skills towards them might not decline.

Interestingly, Connolly and McIsaac [6] identify the stage of romantic relationship as entry to romantic relationships in early adolescence, exploring romantic relationship in middle adolescence and consolidating dyadic relationship bonds in late adolescence. Their study is focused on the adolescence stage of youth, but fails to consider the prospects of a May-December relationship that may form in the academic institution. Their study found central ideas of passion, intimacy, parental and filial influences that shaped a relationship and might determine its outcome.

Frymier and Houser [7] pointed to importance of the teacher-student relationship. Their two pronged studies noted the perceived gender difference to relationship and communication. One of the most important researches made on amorous relationship was the "Romeo and Juliet effect" [8], which covered 140 couples where parental confrontation regarding a relationship tended to solidify an amorous attraction. Indirectly, applied to education their study tested their hypothesis that:

"(a) feelings of love become more highly correlated with trust and acceptance as relationships developed through time and $(b)$ parental interference in a love relationship intensified the feelings of romantic love between members of the couple".

The Frymier and Houser study pointed out that only eighty percent of their participants were able to finish a first session of inquiry. The second session focused on testing the second hypothesis known as the "Romeo and Juliet effect", to determine if their romantic relationship endured after a six-month period. Their study further noted that only a small portion of the original sample size decided to terminate their relationship.

On the legal aspects of relationships between teachers and learners, Sandoval [9] points out that for a qualified seduction case to be punishable under the Philippine laws the presence of an abuse of relationship or authority needs to be present. He points out three classes of offenders: abusers of authority, of confidence and of relationship. The penal code of the Philippines specifically calls out teachers as possible offenders of either simple or qualified seduction.

All these point to existence of a romantic teacher-student relationship, but what of their lived experiences? The pain and the joys of loving? The study is concerned with this growing trend. Higher Educational Institutions have an unwritten policy against such relationships. This study views this phenomenon as urgent to address understanding of the shared experience to develop policies and practices in Higher Educational Institutions regarding teacher-student romantic relationships.

Relevance of the Study This study needs to be conducted as there is an absence of qualitative studies on understanding romantic consensual relationships between students and teachers. This study may prove relevant in providing qualitative answers to ethical questions regarding the teaching profession. This study hopes to become a starting point of discussion among academicians regarding this phenomenon. Students may find the study useful through the application of introspective reading, and in doing so this study may help them understand people engaging in consensual relationships. Finally, society may find this study relevant by enriching their own experiences; possibly society may have a paradigm shift on the negative view point of such relationship.

\section{The Research Questions}

The Research Questions This study is seeks to answer the following questions:

1) What are the "lived experiences" of those engaged in consensual relationships? 
2) What are the informants meaning to the term consensual relationships?

3) What are the thematic experiences of the phenomena?

4) Does a romantic student-teacher relationship vary from the stages developed by Connolly and McIsaac?

\section{Procedures}

Philosophical Approach The study is anchored on the Constructivist world view. Social constructivist [10] believe that people then to seek the meaning, reason and understanding for the world they live in thus varying individuals may produce different meanings, understandings and interpretation of such a phenomena. When we speak of consensual relationship a parent may give a negative-prohibitive definition, a learner may produce a definition anchored on the sweetness of the impossible love. These meanings are believed to be a social creation. It is the Researcher's task to identify how these meaning were developed. Jankowiak and Fischer [11] showed that cultural traditions form part of our own idea's of love hence this study makes use of the Constructivist view. It is for these reasons that the constructivist world view is selected as a philosophical approach for this study.

The study makes use of the procedures to conduct a phenomenology as outlined by Creswell [12] where in the researcher must first determine whether the subject is best suited under the phenomenological approach, the phenomenon must be identified to be of interested according to the researcher's criteria, data was collected from people who had experienced that common phenomena, in making the interview schedule informants were asked two broad/general questions that will become the basis for categorizing their responses by themes, epoch, and finally from these statements an invariant narrative was to describe what made the phenomena as it is. The researcher cannot remain passive rather he must interject his own ideas, experience into the fore of the writing process.

\subsection{Research Design-Qualitative}

This study applies the Interpretive Phenomenological Approach (IPA) developed by Heidegger. Adolfsson et al . [12] believed that in cases of miscarriage, an unquantified experience, IPA is best suited as responses made by informants are representative of their mental state of mind, view point and understanding of the phenomena. Consensual relationships by its nature are unquantifiable experiences, there is no better way to understand an experience but from hear it from source itself.

\subsection{Sampling Methodology}

Sampling Methodology The study made use of twenty sample size equally divided to represent the instructor and learner's side. All informants come from XXX University within the ambit of tertiary education. A combination of purposive sampling and experience sampling Method, as proposed by Larson and Csikszentmihalyi [14] was used. For one to be part of the study the criterion must be met:

- Willingness to share time and answer questions from their personal experience $(25 \%)$.

- Selected informants have experience in consensual relationship between learners and teachers $(25 \%)$.

- Familiarity with the researcher $(50 \%)$

\subsection{Data Collection and Instrument}

Data Collection Procedures and Instrument The following procedures were under taken for data gathering. Once the informants qualified with the conditions set forth in the sampling section, the following actions are observed:

1) Dissemination of selection notices. Informants are notified for an interview schedule at a place and time of their own selection, this is made so that informants can feel at ease thereby sharing more information.

2) Briefing Informants were made to understand the sensitive nature and precarious situation that may arise after the conduct of the study. A mutual non-disclosure agreement was set in place, as well as guarantee to Informants identity were set by using codes, their academic institution is safe guarded by using the nomenclature of XXX University.

3) Scheduling of interview and use of interview protocols.

Interview protocols were observed, Creswell defined it "as a form used by the researcher for recording and writing down information obtained during an interview". Creswell's definition is akin to the one developed by 
Fowler [15] wherein he defined the interview schedule as "an interview schedule is the guide an interviewer uses when conducting a structured interview". From these facts we can surmise that both terms interview protocol and interview guide to be synonymous but since Creswell's definition is latest his terminology was applied to the study.

4) Triangulation will only occur if informant's voluntarily allows usage of his private documents in the form of love letters, pictures and other documentation that they may find helpful for the study.

5) Debriefing

Informants were allowed to go over the researcher's note to identify points of clarification. Creswell calls this procedure as "member checking" as method of validating qualitative data.

6) Call back

An optional process, it is a repetition of step two to three but will only occur when the research finds points of inconsistencies and ambiguity to the raw data collected.

The primary tool of interviews is the interview protocol, wherein its entries may then be recorded with informants consent otherwise note taking is done. The interview guide makes use of two open ended questions like "what is it like to fall in love with a teacher/student?" The researcher makes follow-up questions in line with the responses to get a clear understanding of their lived experiences. The Researcher is the primary instrument of the study, gathering collating and referencing the data culled from informants. Two sessions of interviews were under taken lasting an hour or more per informant.

\subsection{Data Analysis Procedures}

The study used of the phenomenological analysis procedure developed by Moustakas [16]. The following is a detailed process of the analysis: first stage is immersion, this presupposes the research has prior actual experience regarding the phenomena, this issue is addressed in the researcher's reflexive. Secondly, Incubation occurs as a period of recollection undertaken after collecting, recording, transcribing responses to understand insight and develop an understanding of the informant's experiences. Thirdly is Illumination, a process akin to Archimedes Eureka moment where a spark of idea occurs into the researcher mind that signifies understanding of the lived experience of the informants. Fourth, Explication, a reflective process where the researcher reflects on the experience uncovered and asking creative questions to himself like "what would I have done if I were in his shoes?". Finally, the Creative synthesis is a process where the researcher finds common "denomination" of experiences so as to develop a theme that will serve as the basis of the data presentation and discussion which is narrative and possibly exhaustive in scope.

Strategies for Validating Findings Collected interviews are transcribed, a portion of this transcription is shown to the interviewee-informant for checking. The entire transcript cannot be shown to the informants since to do so would tax their time unless they so desire one it will be provided; this validation process is called member checking. Triangulation of data is done by referring it to various sources like pictures, letters, diaries that informants may provide at their leisure. No document was used without prior consent as a safe guard to privacy. The themes so generated were double checked to determine its consonance to the source and raw data.

Anticipated Ethical Issues After reading this study, the researcher anticipates a "witch hunt" among faculties in the academia from whence the researcher originates, possibly the researcher might be accused of romanticizing his students. In order to counteract such hunt, a mutual non-disclosure agreement (MNDA) is formed to protect the informants. The MNDA is a document where the researcher disavows any knowledge that pertains to the identity of the informants. An informed consent form was also furnished to participant informing them of potential risk versus benefits. The site of the study is one devoid of vested interest since venue is placed at informants' selection.

Ethical Review Procedures All instruments used in the study were submitted to University of the Visayas Center for Research and Development for the issuance of an Internal Review Board (IRB) Clearance and an exemption certificate. Prior to the issuance of such document the center under reviews the following documents: interview protocol, non-disclosure agreement, coding notes, transcript of interview. The purpose of the reviewing the documentation is for the following:

a) The center undertakes to determine if the study posses an ethical violation to the rights of the informants.

b) Determine if the statutory rights of informants privacy were protected and identify steps that the research did to protect these. 
c) Protect the participants and the researcher from any identifiable problems that may arise out of the study.

If these conditions are met an IRB clearance and exemption certificates are issued, otherwise the center will suggest corrective measures for ethical consideration.

\section{Presentation and Discussion}

All data collected from informants were classified into three stages: Formation, shaping and closure of a relationship. These trilogy of stages are not the themes rather it is important to show the gamut of experiences by informant's of the study, within these stages so identified, themes are generated to further expound on the "lived experiences".

The Birth of a Consensual Relationship How does an amorous relationship begin between teacher and student? This portion of the study present various supporting tract by identifying the themes unlocked in this stage.

Theme No. 1: Physical Attraction

T No. 1: "She was simply breathtakingly beautiful, her looks was one that would leave me speechless in the middle of my class".

T No. 2: "Beauty and intelligence pare, what more can I ask for in a woman? I sang to her during the Christmas party in guise of saying hello but ended up with going out with her that day!"

T No. 5: "Anyway she's seven years younger than me but get this she often visits me in the office to ask help on her assignments on other subjects. I can't stop looking at her exquisite beauty there are times that she'd touch me like she'd always try to grasp my hands when submitting assignments. Oh she'd even brush her boobs accidentally to my elbows, something like that".

$S$ No. 9: "He was actually smart. I was more attracted to his intelligence more than anything".

S No. 5: "Boy my teacher was so sexy, especially when she writes on the board you can see that tight shape of her ass".

On a lighter note, one of the female-student informant's shared an amusing start to a relationship, she claimed that while lecturing her teacher's saliva would often fly out of his mouth. All this occurred while she was busy talking with her friend about someone love life, the teacher in question would often move in a bid to get everyone's attention, when out of the blue a speck of his saliva entered her mouth while talking, she jokingly points out that it may be the reason why she fell in love with him in the first place. Still, on the lighter side of things a male-teacher informant claimed that during discussion a student would secretly raise her skirt for him to see her underwear. He surmised the student was trying to see if he would blush at such sight, instead him reminded that student, while discussing in class, to seat properly as her soul was visible to his eyes. These vignettes shows that physical attraction is a basis for sexual attraction among males informants whereas for female informants. This seems to verify the findings of Pease and Pease [17] where they proved that sex is a primary consideration for selecting a partner for men whereas for women it is about what a man provides her with.

At the start of relationship, It was noted that female students would give tell-tale signs to teacher's about their interest to start a romantic relationship, it is when the instructor notices these signs that he initiates contact with the student to graduate their relationship from teacher-student to lovers.

\section{Theme No. 2: Fatalistic Attraction}

S No. 5: "I believe that God brought us together. When he was teaching I did give mind to his passes to me, like greeting hello and texting. It was when we started talking together that I felt that we had a connection. He can complete my words even before the words came out of my mouth".

The theme of fatalistic attraction is a rare occurrence in the study, since it is supported by one track only however in the bid to show uniqueness this theme it was so included. This tract came from a young college lady who fell in love with her teacher. The researcher surmises that such belief is attributed to the books that informants read. It was helpful to view the various romantic literatures that an informant has in her home, she even showed a few of this books to the researcher. Romantic books owned by informants ranged from Mills and Boon, Daniel Steele and Syndney Sheldon. Possibly these ideas affected her perception of falling in love.

\section{Theme No. 3: Transference}

S No. 2: "I was initially attracted to him as he looks, acts, and thinks like my ex a few years back".

$S$ No. 8: "I just came from a bad relationship, where I was abused verbally. She reminded me of my first love to a certain extent".

The theme of transference is one where attraction exists when we tend to transfer our affection from one per- 
son to another. It usually occurs when the original object of our affection is not treated mutually by the original object of our affection. It is not necessary that the new object of one's affection must possess an entire totality of personality, even a few common traits is enough. In the presented tracts, informants mentally choose to fall for their teacher as they remind them of someone they used to admire, love or care for. They consider it a mere bonus for such affections to be mutually reciprocated.

\section{Theme No. 4: Countertransference}

T No. 3: "I used to go out with another student that relationship ended bitterly but when I fell for another student I found myself asking her to go to places that I used to hang out with my ex. It's unfair of me but I can't explain why I do these things".

T No. 9: "It wouldn't matter of me if she was married or not. At the back of my mind I was thinking if I can make this work, it's like I made my previous relationship work. Like saying a big F-U to that student who dumped me".

These selected tracts show countertransference. It is the reversal of transference but occurs to the person in power or authority of a relationship. In the common parlance, these actions are considered as "rebound relationship" akin to a basketball game where the ball represents someone who losses but is given another chance. Strictly speaking this kind of affection is not total affection as the informants are not really in love with the object of their affection; instead, they are in love with the concept of staying in love; as if the whole point of being in a relationship becomes more of a need than a necessity. It is this factor that give rise to blurring of societal roles.

During the Consensual Relationship This part focuses on the trials, activities, hardships that informants undergo in a consensual relationship between student and teachers. It was noted that only three out of twenty informants were able to graduate their relationship to the legal union called matrimony.

Theme No. 5: Blurring of Societal Roles Below are snippets of the interview schedule taken from student informant's that shows instances when the teacher over steps his role in the class room. Often time they feel an abuse of power.

S No. 7: "I was supposed to meet up in (name of mall) with him after our class but I was given a special gift by another suitor, it was a brand new cell phone, somehow he found about it. The next day we had an oral exam, he was very livid when I did not give him the correct answer and he warned me that I should focus more on my studies but I knew he was getting revenge over that canceled date".

S No. 4: "He was my computer teacher back then we were about to do it in the evening at some motel. Earlier in the afternoon, I passed by his computer lab little did he know I was looking behind him. I noticed he was looking for information about contraception, I found it cute that I had to kiss him quickly, good thing no one was around us".

S No. 9: "... heard from a few friends that they were saying he was a playboy and most girl noticed his advances to them. I got angry for their loose tongue and started to defend him. They didn't know how sweet, and caring he is".

In these instances, it is noted that the teacher engaged in consensual relationship tend to combine his dual role as a teacher and as a paramour into a single phenomena whereby each of these are integrated to the formation of his lived experience regarding consensual relationships. This theme of blurring societal roles only applies to a partner in a consensual relationship who has authority and power over the other.

Theme No. 6 Secrecy Parties to a consensual relationship have varied ways of spending time together outside the prying eyes of co-workers, friends and others. It is enlightening, to identify the various methods they employ to keep the confidential nature of their relationship; not so that we may use it; instead such information gives us a better understand of how the phenomena occurs. Below are some tracts that best exemplify this theme:

T No. 7: "We would text each other about for our meeting place, it could be a mall or a movie house".

S No. 3: "Back when we were together, he would reserve a place for us in a (name of hotel). I would usually meet him in the evening, we spend the night there. It was our special and private time together".

S No. 6: "We kept our relationship secret by renting a small apartment just for the two of us. We made sure to move at different times, let's say he goes to work at six and go at eight".

$T$ No. 8: "I would usually pick her up in my car, yes it is tinted for privacy purposes. In rare case, we do hail a cab but its either I am riding first or her, we pick up each other on a random place with few people".

The Philippine culture considers consensual relationship as a taboo more so for living together. Due to the level of intrigues that may damage the reputation they are forced to keep it hidden from the prying eyes of so- 
ciety. Various methods were employed like the usage of private messaging to social network, use of cars with tints for privacy, meeting in a hotel room; all this points to the basic fact that their relationship is frowned up by society. The various risk that entails it are acknowledged by the parties.

The End Is the Beginning of a Relationship or Is It? "How does a consensual relationship end?" "How can you forget someone who has you so much to remember?" These are some of the inner thoughts that come to mind. In all of our informants, especially the students in the relationship would not dare to break-up with their teacher in the middle of the academic period for fear of reprisal in the form of an incomplete grade, a failing mark.

Theme No. 7 Fear

S No. 6: "I was only using him for that particular semester hi hi hi It was hard enough to pass his subject especially that he was a noted professor who failed many, I did what I had to do".

S No. 8: "I had relationship with 2 teachers and most of them were suffering from disability; one was without a hand and the other had polio. You know what's more amusing they never lasted one semester oh they do spoil me by giving expensive gifts and free food. You want to know how we broke up? I never talked with him, just like that".

T No. 4: "We lasted for two semesters. She had a child out of wedlock, knocked up by some guy from their band in their Christian Community. I guess we broke up as she was never able to forgive me I said something about her that maybe insulted her pride as a mother so much that I was never given a second chance, just a letter of close and that's what it was".

T No. 9: "Well, we never broke up yes there were instance that we wanted to give up on each other but I guess we love each other so much through thick and thin, and we eventually got married. Your asking if any teacher knows about it? Only close very close people that I trust with my life that's how I did it".

S No. 10: "I still remember him proposing to me, he had this huge crowd who sang at my terrace probably his students; no I was a head of this group of student so they never have an idea that I was his student before".

\section{Conclusions}

The study found that very few of the consensual relationships between learners and their instructors had a happy ending. It must be noted that students are aware of the fact that their grades hinge on the quality of their relationship with their teachers. Hence, teachers must take into consideration these cautionary tales of short love affairs. The study found that the relationship model of Connolly and McIsaac's was present as informants treated the relationship on a similar level to a romantic relationship, although informants used extreme methods to protect privacy. Ultimately when the relationship ended, it became a public knowledge to people around them.

Consensual relationships do exist between teachers and students, despite various rules and sanctions imposed. So, people in love will find a way to overcome hindrances to loving.

\section{Authors and Affiliations}

The author is a faculty of University of the Visayas under the College of Arts and Sciences department, teaching various social science subjects and post graduate subjects in education. He is also the research coordinator for the aforementioned department.

\section{Acknowledgements}

The author wishes to thank the informants and his family for the understanding the long hours of writing, interviewing and sharing of experiences, the same is also due to the University of the Visayas Cebu Philippines Dr. Estrella C. Navarro Dean of College of Arts and Sciences and Dr. Brian Vasquez for the confidence.

\section{References}

[1] Stake, J.E. and Noonan, M. (1985) The Influence of Teacher Models on the Career Confidence and Motivation of College Students. Sex Roles, 12, 1023-1031. http://dx.doi.org/10.1007/BF00288102

[2] Guralnik, D. (1970) Webster's New World Dictionary of the American Language. 2nd College Edition, Word Publishing Company, New York.

[3] Gabbard, G.O. (1994) On Love and Lust in Erotic Transference. Journal of the American Psychoanalytic Association, 


\section{2, 385-386. http://dx.doi.org/10.1177/000306519404200203}

[4] Freud, S. (1957) The Future Prospects of Psycho-Analytic Therapy. In: The Standard Edition of the Complete Psychological Works of Sigmund Freud: Five Lectures on Psycho-Analysis, Leonardo da Vinci and Other Works, Vol. 14, Hogarth Press, London, 139-152.

[5] Smith, R.C. (1984) Teaching Interviewing Skills to Medical Students: The Issue of "Countertransference". Academic Medicine, 59, 582-588. http://dx.doi.org/10.1097/00001888-198407000-00007

[6] Connolly, J. and McIsaac, C. (2011) Romantic Relationships in Adolescence. Social Development: Relationships in Infancy, Childhood, and Adolescence, The Guilford Press, New York, 180-206.

[7] Frymier, A.B. and Houser, M.L. (2000) The Teacher Student Relationship as an Interpersonal Relationship. Communication Education, 49, 207-219. http://dx.doi.org/10.1080/03634520009379209

[8] Driscoll, R., Davis, K.E. and Lipetz, M.E. (1972) Parental Interference and Romantic Love: The Romeo and Juliet Effect. Journal of Personality and Social Psychology, 24, 1-10. http://dx.doi.org/10.1037/h0033373

[9] Sandoval, E.G. (2007) Pointers in Criminal Law. Rex Printing Company, Manila.

[10] Creswell, J.W. (2014) Research Design. 4th Edition, Sage Publications, Thousand Oak.

[11] Jankowiak, W.R. and Fischer, E.F. (1992) A Cross-Cultural Perspective on Romantic Love. Ethnology, 31, $149-155$. http://dx.doi.org/10.2307/3773618

[12] Creswell, J.W. (2006) Qualitative Inquiry and Research Design: Choosing among Five Approaches. Sage Publications, Thousand Oaks.

[13] Adolfsson, A., Tullander-Tjörnstrand, K. and Larsson, P.-G. (2011) Decreased Need for Emergency Services after Changing Management for Suspected Miscarriage. Acta Obstetricia et Gynecologica Scandinavica, 90, 921-923. http://dx.doi.org/10.1111/j.1600-0412.2011.01144.x

[14] Larson, R. and Csikszentmihalyi, M. (1983) The Experience Sampling Method. New Directions for Methodology of Social \& Behavioral Science, 15, 41-56.

[15] Fowler, F. (2004) Interview Schedule. In: Lewis-Beck, M., Bryman, A. and Liao, T., Eds., Encyclopedia of Social Science Research Methods, Sage Publication Inc., Thousand Oaks, 519-520. http://dx.doi.org/10.4135/9781412950589.n451

[16] Moustakas, C. (1994) Phenomenological Research Methods. Sage, Thousand Oaks.

[17] Pease, A. and Pease, B. (2010) The Mating Game: Why Men Want Sex and Women Need Love. Orion Press, London. 
Scientific Research Publishing (SCIRP) is one of the largest Open Access journal publishers. It is currently publishing more than 200 open access, online, peer-reviewed journals covering a wide range of academic disciplines. SCIRP serves the worldwide academic communities and contributes to the progress and application of science with its publication.

Other selected journals from SCIRP are listed as below. Submit your manuscript to us via either submit@scirp.org or Online Submission Portal.
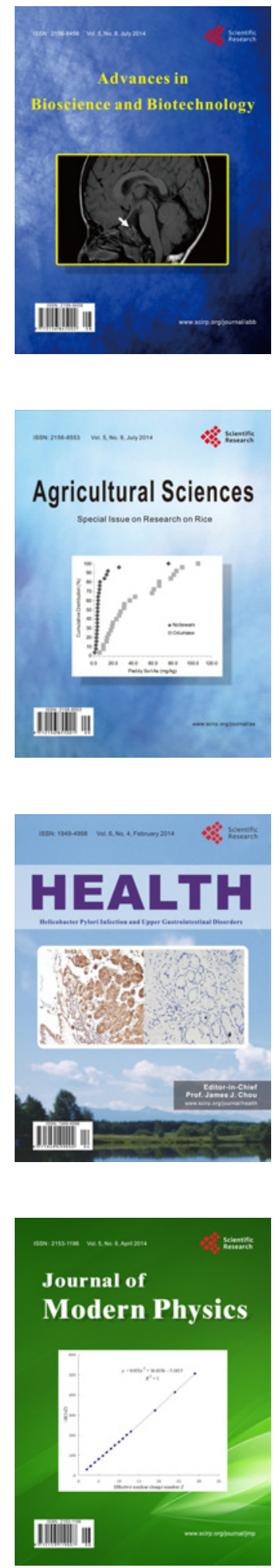
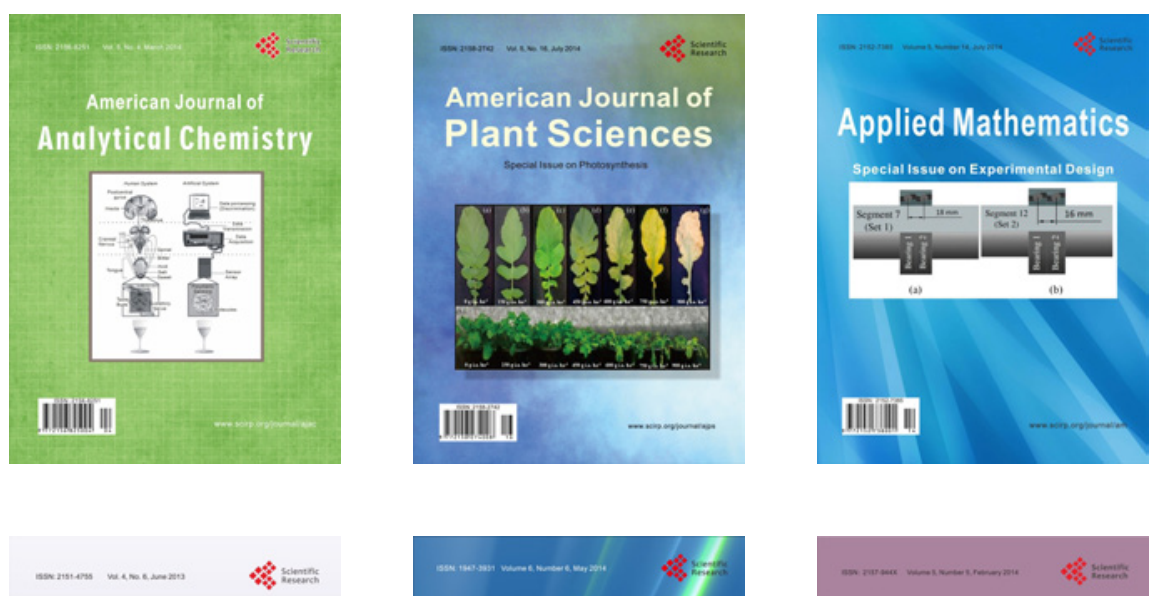

Creative Education
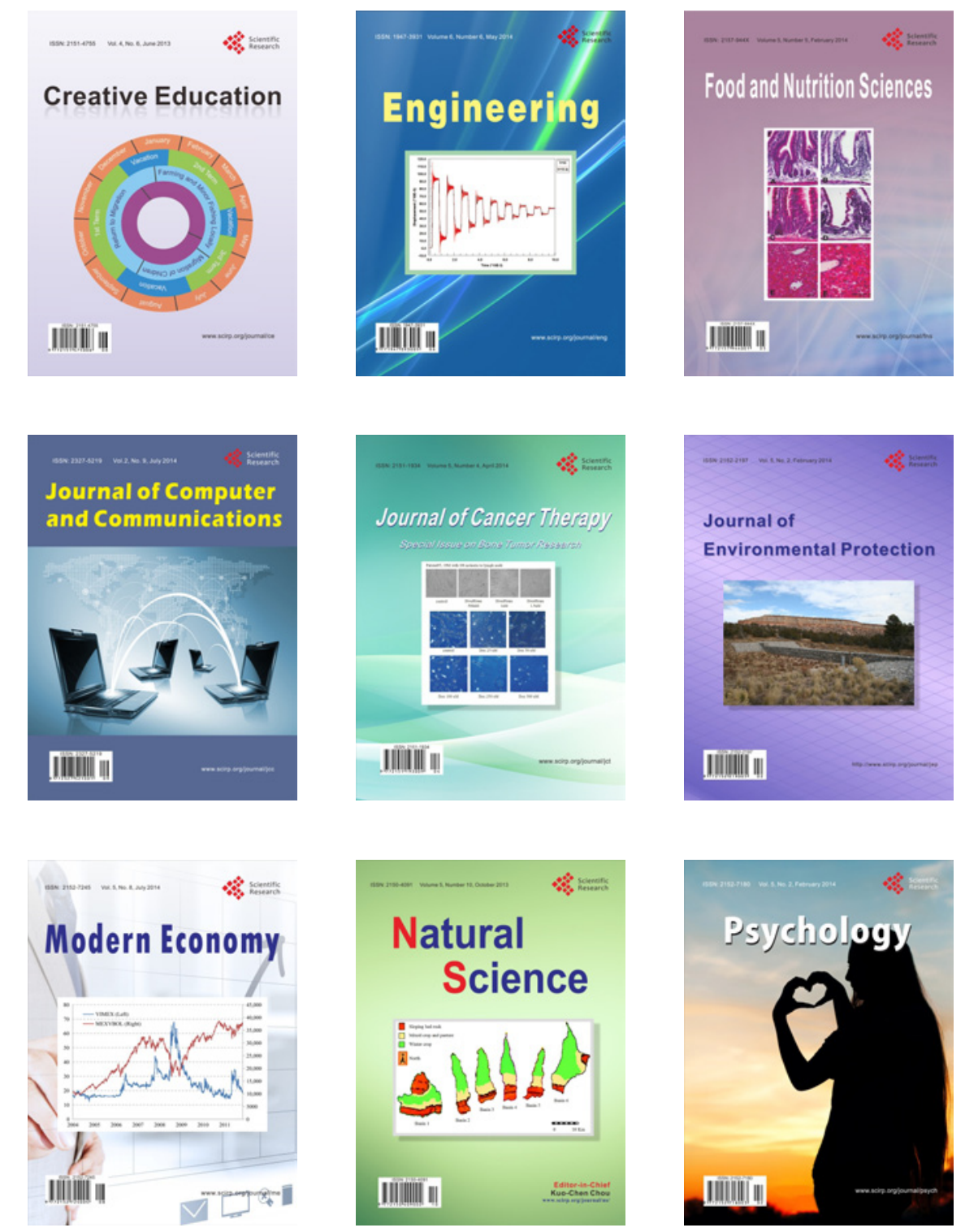